\title{
Soil microbes drive the classic plant diversity-productivity pattern
}

\author{
Stefan A. Schnitzer, ${ }^{1,2,10}$ John N. Klironomos, ${ }^{3}$ Janneke HilleRisLambers,${ }^{4}$ Linda L. Kinkel, ${ }^{5}$ Peter B. Reich, ${ }^{6}$ \\ Kun Xiao, ${ }^{5}$ Matthias C. Rillig, ${ }^{7}$ Benjamin A. Sikes, ${ }^{8}$ Ragan M. Callaway, ${ }^{9}$ Scott A. Mangan, ${ }^{1,2}$ \\ Egbert H. van Nes, ${ }^{10}$ and Marten Scheffer ${ }^{10}$ \\ ${ }^{1}$ Department of Biological Sciences, University of Wisconsin, P.O. Box 413, Milwaukee, Wisconsin 53201 USA \\ ${ }^{2}$ Smithsonian Tropical Research Institute, Apartado 0843-03092, Balboa, Panama \\ ${ }^{3}$ Biology and Physical Geography Unit, University of British Columbia-Okanagan, Kelowna, British Columbia V1V 1 V7 Canada \\ ${ }^{4}$ Biology Department, University of Washington, Seattle, Washington 98195 USA \\ ${ }^{5}$ Department of Plant Pathology, University of Minnesota, St. Paul, Minnesota 55108 USA \\ ${ }^{6}$ Department of Forest Resources, University of Minnesota, St. Paul, Minnesota 55108 USA \\ ${ }^{7}$ Institut für Biologie, Freie Universitaet Berlin, Altensteinstr. 6, D-14195 Berlin, Germany \\ ${ }^{8}$ Section of Integrative Biology, University of Texas, Austin, Texas 78705 USA \\ ${ }^{9}$ Division of Biological Sciences, The University of Montana, Missoula, Montana 59812 USA \\ ${ }^{10}$ Aquatic Ecology and Water Quality Management, Wageningen University, Wageningen, The Netherlands
}

Abstract. Ecosystem productivity commonly increases asymptotically with plant species diversity, and determining the mechanisms responsible for this well-known pattern is essential to predict potential changes in ecosystem productivity with ongoing species loss. Previous studies attributed the asymptotic diversity-productivity pattern to plant competition and differential resource use (e.g., niche complementarity). Using an analytical model and a series of experiments, we demonstrate theoretically and empirically that host-specific soil microbes can be major determinants of the diversity-productivity relationship in grasslands. In the presence of soil microbes, plant disease decreased with increasing diversity, and productivity increased nearly $500 \%$, primarily because of the strong effect of density-dependent disease on productivity at low diversity. Correspondingly, disease was higher in plants grown in conspecific-trained soils than heterospecific-trained soils (demonstrating host-specificity), and productivity increased and host-specific disease decreased with increasing community diversity, suggesting that disease was the primary cause of reduced productivity in speciespoor treatments. In sterilized, microbe-free soils, the increase in productivity with increasing plant species number was markedly lower than the increase measured in the presence of soil microbes, suggesting that niche complementarity was a weaker determinant of the diversityproductivity relationship. Our results demonstrate that soil microbes play an integral role as determinants of the diversity-productivity relationship.

Key words: AMF; density dependence; diversity-productivity; negative feedback; pathogens; soil microbes; species richness.

\section{INTRODUCTION}

The idea that plant communities with high species diversity are more stable and productive has a long history in ecology (e.g., Naeem et al. 1994, Tilman et al. 1997, 2001, Wardle 2002, Hooper et al. 2005). Contemporary explanations for the asymptotic increase in ecosystem productivity with diversity have focused primarily on resource competition and utilization, mainly via "niche complementarity" or "sampling effects" (Huston 1997, Tilman et al. 1997, 2001, Hooper and Dukes 2004, Fargione et al. 2007). The niche complementarity argument posits that the presence of many species and functional types results in more complete utilization of resources because different species specialize on different resources, resulting in

Manuscript received 17 April 2010; revised 2 August 2010; accepted 3 September 2010. Corresponding Editor: G. S. Gilbert.

${ }^{10}$ E-mail: Schnitzer@uwm.edu higher overall productivity (Tilman et al. 1997, 2001, HilleRisLambers et al. 2004). The sampling effect argument posits that species identity may be more important than diversity per se, asserting that productivity increases with diversity solely due to an increased probability that communities with more species contain a few very productive species that disproportionately contribute to community-wide productivity (Huston 1997, Wardle 2002). Both explanations are based on the assumption that resource availability and utilization drive the positive asymptotic diversity-productivity relationship.

Both niche complementarity and sampling effects may contribute to the positive diversity-productivity relationship (Huston 1997, Fargione et al. 2007), but it is becoming increasingly clear that soil microbes also play a role in regulating plant communities and thus may contribute to the diversity-productivity relationship (Klironomos 2002, Mitchell et al. 2002, 2003, van der Heijden et al. 2008). For example, soil mutualists, such 
as arbuscular mycorrhizal fungi (AMF), may contribute to the positive diversity-productivity relationship by increasing per capita plant productivity with increasing diversity (van der Heijden et al. 2008). AMF may increase productivity by enhancing plant resource uptake, through resource sharing via AMF networks, and by protecting plant hosts from soil pathogens (Koide 1991, Simard and Durall 2004, Sikes et al. 2009). Plant species richness is positively correlated with AMF richness, and higher AMF richness has been shown to increase plant productivity (Klironomos et al. 2000).

Soil-borne pathogens, which are typically less mobile than foliar pathogens and herbivores, may have particularly strong negative density-dependent effects on productivity at low diversity by infecting conspecifics that are in close proximity to each other, and thus reducing per capita and ecosystem-level plant growth (Bever et al. 1997, Knops et al. 1999, Klironomos 2002, Mitchell et al. 2002, Kulmatiski et al. 2008). In more diverse communities, however, soil-borne disease may be less prevalent because there is a lower likelihood of growing near a conspecific, and there are lower concentrations of host-specific soil enemies (Mitchell et al. 2002, 2003). If species-specific pathogens limit per capita biomass through density-dependent regulation (e.g., Mills and Bever 1998), then as species richness increases, disease should decrease and plant productivity should increase, even in the absence of niche complementarity or sampling effects (Maron et al., in press).

To illustrate these concepts and to generate predictions for how pathogens may affect the diversityproductivity relationship, we used a simple model adding the effects of density-dependent losses resulting from pathogens to the classical Lotka-Volterra competition equation:

$$
\frac{d N_{i}}{d t}=r N_{i}\left(K_{i}-\sum_{j} \alpha_{i, j} N_{j}\right) / K_{i}-m \frac{N_{i}^{p}}{N_{i}^{p}+H^{p}}
$$

where $N_{i}$ is the density of the species $i, r$ is the maximum per capita growth rate, $K_{i}$ is the carrying capacity of species $i$, and $\alpha_{i, j}$ is the competition coefficient, which scales the effect of species $j$ on species $i$. The effect of pathogen regulation is represented in the last term of the equation, where pathogen-induced losses are assumed to increase relatively steeply (up to a maximum $m$ ) when population density exceeds a threshold $(H)$. The superscripts $p$ of $N$ and $H$ stand for "pathogen"; they distinguish the pathogen-specific variables. Pathogeninduced losses were excluded by setting $m=0$ and were included by setting $m=1$. We generated hypothetical communities of coexisting species by randomly drawing the competition coefficients $\left(\alpha_{i, j}\right)$ and analyzed how the biomass of stable communities was related to their number of species. We generated non-neutral models by selecting competition coefficients $(\alpha)$ randomly (between 0 and 0.5 ) and neutral models by constraining $\alpha$ between 0.9 and 1.0 (see Appendix A for more details).

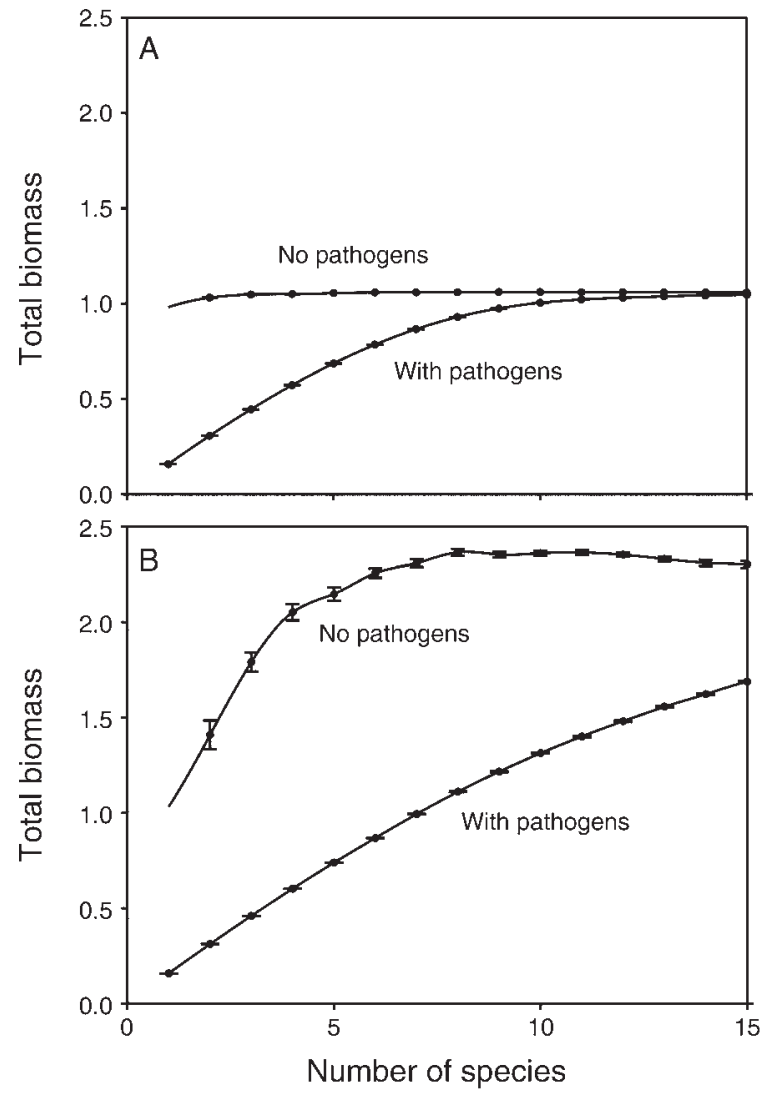

Fig. 1. Theoretical relationships between species number and biomass generated by a modified Lotka-Volterra model with and without the effect of pathogens (Eq. 1). Panel A represents neutral competition (uniformly distributed competition terms $[\alpha]$ between 0.9 and 1). Panel B represents competition (uniformly distributed $\alpha$ between 0 and 0.5 ). Curves were generated by spline interpolation, and error bars represent \pm SE.

We first generated a competitively neutral model and, when pathogen-induced losses were excluded, we found that community biomass was unrelated to species number (Fig. 1A). In contrast, when pathogen-induced losses were included in the model, the biomass of singlespecies communities was low and total biomass increased asymptotically with species number (Fig. 1A). In this situation, pathogens limited biomass at low diversity, but the effect of pathogens diminished with increasing diversity and competition for resources eventually limited community biomass, resulting in the well-known saturating diversity-productivity curve. For comparison, we also generated non-neutral (partial niche overlap) communities with and without pathogens. We found that in the absence of pathogens, niche complementarity can lead to the same classical pattern of asymptotically increasing biomass with species number (Fig. 1B). The two mechanisms combined (pathogens and niche complementarity) suppressed biomass more than either mechanism alone, which resulted in a more linear increase in productivity with 
diversity (Fig. 1B), with the biomass saturation point appearing at higher diversity (not shown).

Because both density-dependent disease and competition can theoretically generate the classic asymptotic increase in productivity with diversity (Fig. 1A, B), we used two complementary experiments to determine how plant disease and productivity vary over a gradient of plant species richness in the presence and absence of different groups of soil microbes, and whether feedback between plants and soil biota influenced the diversityproductivity pattern. In the first experiment, we tested whether the classic asymptotic diversity-ecosystem productivity relationship arose in the presence and absence of soil pathogens, parasites, and saprobes or arbuscular mycorrhizal fungi (AMF). In the second experiment we tested: (1) whether soil biota were hostspecific to plants, and (2) whether the effects of soil biota on plant productivity and disease varied with increasing plant diversity.

\section{Methods}

Experiment 1 was conducted at the University of Guelph, Ontario, Canada, where we assembled herbaceous plant communities at four different diversity levels $(1,5,10$, and 15 species) by randomly selecting seeds from a pool of 35 relatively common species that, combined, have a large contribution to ecosystem productivity (Appendix D). We grew the plant communities in large, outdoor, self-contained pots $(1 \times 0.75 \times$ $0.5 \mathrm{~m}$ deep) that held $90 \mathrm{~kg}$ of a 1:1 mixture of gammairradiated (or untreated) field soil and silica sand. For each diversity level we imposed four different soil treatments. (1) Field soil, which was collected directly from the field and was not manipulated. (2) Sterile field soil, which was field soil that was gamma-irradiated (thereby killing soil biota). (3) AMF-enriched soil, which was sterile field soil with the addition of AMF spores (mixed AMF species). (4) Pathogen-enriched soil, which was sterile field soil with the addition of the pathogen/ parasite/saprobe fraction isolated from field soil. The AMF spores and the pathogen/parasite/saprobe fraction were collected from multispecies prairie soils located at the University of Guelph.

Plants were allowed to grow for 20 weeks, after which they were harvested, oven-dried $\left(60^{\circ} \mathrm{C}\right.$ for 48 hours), and then weighed (shoots and roots) to determine productivity. We separated plant shoots by species and determined aboveground community productivity. Following harvest, we randomly collected $100,3-5 \mathrm{~cm}$ long root fragments from each mesocosm and stained them with Chlorazol Black E (Brundrett et al. 1984) to determine colonization by AMF and infection by nonAMF (members of the ascomycota and basidiomycota) using the magnified intersect method (McGonigle et al. 1990). See Appendix B for additional details.

We analyzed data for experiment 1 in two steps. First, we used a factorial analysis of variance (ANOVA) with soil treatment and plant species richness as explanatory variables and plant productivity as response variables to explore how different microbe functional groups, diversity, and their interaction influence plant productivity. Next, we fitted linear, power, log, exponential, and polynomial functions to the relationship between species richness and total productivity (separately for each soil treatment), to explore how microbes alter the shape of that relationship. We calculated Akaike information criterion (AIC) for each of these five models, choosing the model with the smallest AIC value. If the difference in AIC between several models was $<2$, then those models were considered not significantly different from each other (Motulsky and Christopoulos 2004).

Experiment 2 was conducted at Cedar Creek Ecosystem Science Reserve, Minnesota, USA. We capitalized on a long-term biodiversity experiment to test whether: (1) soil biota cause more disease in plants grown in conspecific-trained soils than in heterospecific-trained soils (host-specificity); and (2) plant productivity increases and soil-borne disease decreases with increasing plant diversity. We grew six different species of perennial grassland plants in soils collected from 66 plots, $2 \times 2 \mathrm{~m}$ in dimension, and each consisting of a 5-year-old plant community composed of either a single-species monoculture containing one of the six target species, or containing a randomly selected set of 4 or 16 species in which the target species was present (see Reich et al. 2001).

First, we tested host specificity of soil-borne disease by growing individual seedlings of each target species in separate pots containing soil collected from either conspecific ("home" treatment; $n=48$ ) or heterospecific ("away" treatment; $n=49$ ) monoculture plant communities. Second, we tested whether increasing plant diversity increased per capita productivity and reduced soil-borne disease by planting each of the six target species individually in separate pots in soils from the three different diversity levels (1, 4, or 16 species). Replication consisted of 48,55 , and 45 individuals for the 1-, 4-, and 16-species plots, respectively, and conspecifics of the target species had been present in the plant community for each diversity level. We visually quantified the incidence of root disease (DI; the number of lesions per root) and the disease severity index (DSI; the proportional area of root disease) for each plant. Although visual disease estimates may underestimate disease effects on plant growth, it provides a consistent estimate of fungal damage among treatments (Mitchell 2003), and thus enabled us to attribute our results to pathogens and parasites, rather than saprobes or AMF. This experimental design allowed us to examine the combined effects of soil enemies (pathogens, parasites, and fauna), saprobes, and mutualists, while removing such confounding factors as increased competition, biomass, and altered tissue chemistry, all of which are found in situ (Naeem et al. 1994, Reich et al. 2001, 
Bradford et al. 2002). See Appendix B for additional details.

We analyzed data for experiment 2 using linear models, with plant species identity and soil treatment ("home" or "away" monocultures) or plant diversity (species richness) as explanatory variables, and disease incidence, disease severity, or seedling biomass as response variables. Plant diversity was treated as a categorical explanatory variable, after initial model fitting indicated productivity and disease responses to diversity were not linear. First, we log-transformed both disease severity and productivity values (after adding a small nonzero amount to DSI) to conform to assumptions of normality. Next, we used model selection techniques to identify the minimal number of explanatory variables (species identity, soil treatment/diversity, or both) needed to explain response variables. We did this by fitting the following five linear models to each response variable and analysis: (1) species identity, soil treatment (or diversity), and their interaction; (2) main effects of species identity and soil treatment (or diversity); (3) effects of species identity; (4) effects of soil treatment (or diversity); and (5) a null model with just one parameter (the overall mean). We used model AICs, which balance model fit with parsimony, to select the most appropriate of these five linear models. Consistent with experiment 1 , the model with the smallest AIC value was considered the best fit to the data, and differed significantly from the others if the difference in AIC was $\geq 2$. We calculated $F$ values (from ANOVAs) and associated $P$ values and coefficients from these best-fitting models to interpret our results. For models with diversity as an explanatory variable, we specified contrasts to test for differences among each of the pair-wise diversity treatments, using $t$ values and associated $P$ values to interpret results. We used Bonferroni correction to assess significance for these post hoc comparisons $(\alpha=0.0167$ rather than 0.05$)$. We used ANOVA to test whether soil $\mathrm{N}$ mineralization and soil solution $\mathrm{N}$ concentration varied with diversity in the sampled plots.

\section{REsUlts}

In experiment 1 , plant productivity varied significantly with diversity $\left(F_{3,64}=523.2 ; P<0.0001\right)$ and soil treatment $\left(F_{3,64}=66.7 ; P<0.0001\right)$. The effect of diversity on productivity was much greater when detrimental soil microbes were present than when these microbes were absent (Fig. 2), as indicated by a significant interaction between diversity and soil treatment $\left(F_{9,64}=12.4 ; P=0.0001\right)$. Moreover, a strongly saturating diversity-productivity relationship, the classic pattern reported in other studies (Tilman et al. 1997, 2001, Fargione et al. 2007), was strongest when detrimental soil microbes were present (Fig. 2; green circles and blue triangles), weak when only AMF were present (Fig. 2; red diamonds), and absent in the sterile soils where microbes were largely absent (Fig. 2; black squares).

Detrimental soil microbes limited plant productivity, particularly at low plant diversity where the effects were pronounced. As a result, plant productivity in the presence of these soil biota was nearly $500 \%$ higher in the 15-species communities than in monocultures, with similar patterns found in both the field soil containing all soil biota and the sterilized + pathogen treatment (Fig. 2; Appendix D). The percentage of root infection by non-mycorrhizal (pathogenic/parasitic/saprophytic) fungi was significantly lower in the high-diversity communities compared to the monocultures for the field soil and the sterilized + pathogen treatment (Table 1). In sterilized soils, where only minimal levels of microbes were detected (Table 1), productivity increased linearly and more modestly (by $\sim 30 \%$ ) with increasing plant diversity (compared to 500\% increase with pathogens present; Fig. 2), suggesting that niche complementarity played a subordinate role to soil pathogens in driving the classic diversity-productivity pattern detected in the field soils. The addition of AMF to sterile soil increased productivity at all diversity levels except in monoculture (compared to sterile soils), suggesting that, in the absence of pathogens, AMF may have a greater influence at higher diversity (see also Appendix C).

Effects of soil biota on the plant diversity-productivity relationship in experiment 1 can be explained if: (1) individual plants experience negative feedback with host-specific soil biota (i.e., host-specific soil biota associated with established plants cause more disease in neighboring conspecific relative to heterospecific plants); and (2) individual plants, on average, experienced less soil-borne disease and more per capita productivity with increasing diversity. Our second experiment supports both of these conditions. First, disease severity (the proportional area of root disease) was higher in "home" soils, demonstrating that soilborne microbes have host-specific effects in grassland plants. Seedlings grown in their own "home" monoculture soils had $54 \%$ greater disease severity in their roots than those grown in the soil of another species $\left(F_{1,90}=\right.$ $5.73, P=0.019$; Fig. 3A). Disease incidence (the number of disease lesions on the roots) showed a similar trend (20\% greater disease incidence; Fig. 3B), but did not differ significantly among the treatments $\left(F_{1,90}=2.34, P\right.$ $=0.13$ ). There were no significant species $\times$ treatment interactions, demonstrating that all species responded in a similar manner and no single species was responsible for the observed patterns. We detected a 5\% increase in mean per capita plant productivity in "away" soils compared to "home" soils (Fig. 3C), but this difference was not significant, possibly because resources were not limiting in this experiment and thus plant productivity was less affected by disease.

Second, across the diversity gradient, per capita productivity in plants grown in soil from the most

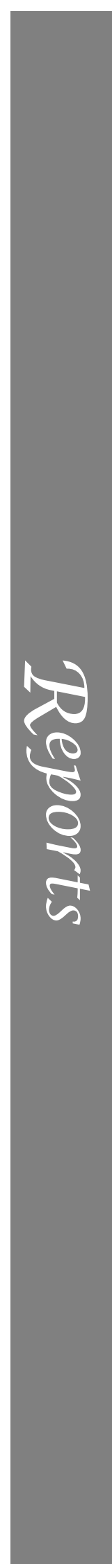




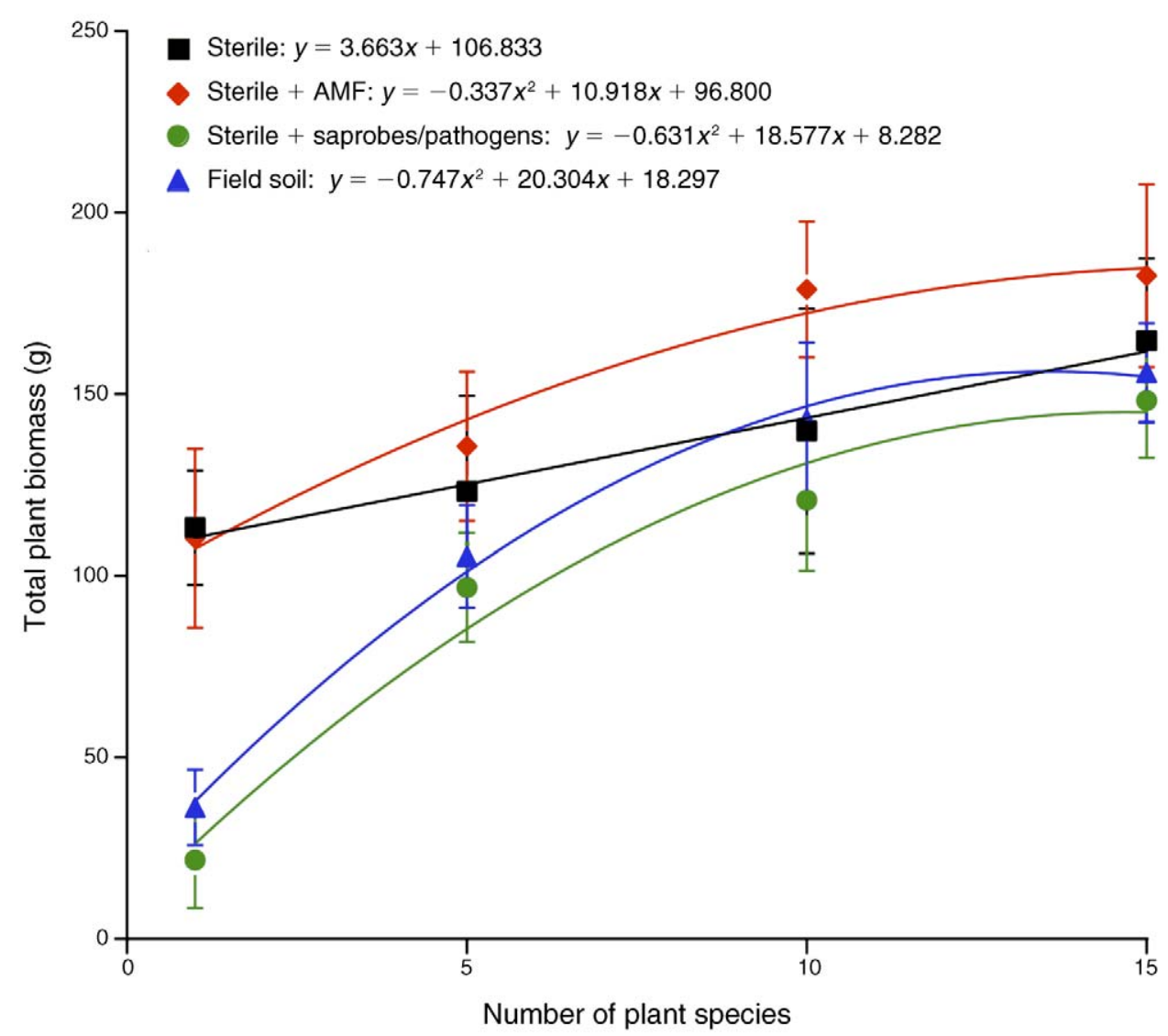

FIG. 2. The relationship between plant diversity and productivity (in grams) in four experimental soil types. Key: sterile (black squares), sterilized field soil; sterile + AMF (red diamonds), sterilized field soil + field-collected AMF spores; sterile + pathogens/ parasites/saprobes (green circles), sterilized field soil + microbial fraction that excludes AMF $(<20 \mu \mathrm{m})$; field soil (blue triangles), untreated field soil. Productivity varied significantly with diversity (ANOVA, $\left.F_{3,64}=523.2, P=0.0001\right)$, soil treatment $\left(F_{3,64}=66.7\right.$; $P=0.0001)$, and the interaction $\left(F_{9,64}=12.4 ; P=0.0001\right)$. Lines represent the best fit with linear and polynomial functions (AIC for sterile soils $=0.04 ; \mathrm{AIC}$ for sterile soils $+\mathrm{AMF}=2.97$; AIC for sterile soils + pathogens $=9.86$; AIC for field soils $=9.91$ ). Error bars represent \pm SE.

TABLE 1. Results from experiment 1; colonization of roots by arbuscular mycorrhizal fungi and infection of roots by non-mycorrhizal (pathogenic/parasitic/saprophytic) fungi.

\begin{tabular}{|c|c|c|c|c|}
\hline \multirow[b]{2}{*}{ Soil treatment } & \multicolumn{4}{|c|}{ Plant species-richness treatment } \\
\hline & 1 & 5 & 10 & 15 \\
\hline \multicolumn{5}{|l|}{ Sterile } \\
\hline Mycorrhizal colonization (\%) & $0^{\mathrm{a}}(0)$ & $0^{\mathrm{a}}(0)$ & $0^{\mathrm{a}}(0)$ & $0^{\mathrm{a}}(0)$ \\
\hline Non-mycorrhizal infection (\%) & $2.4^{\mathrm{a}}(1.2)$ & $1.5^{\mathrm{a}}(1.4)$ & $2.1^{\mathrm{a}}(1.1)$ & $2.6^{\mathrm{a}}(2.3)$ \\
\hline \multicolumn{5}{|l|}{ Sterile + AMF } \\
\hline Mycorrhizal colonization (\%) & $18.4^{\mathrm{a}}(3.1)$ & $26.2^{\mathrm{a}}(3.3)$ & $14.9^{\mathrm{a}}(4.3)$ & $24.4^{\mathrm{a}}(5.1)$ \\
\hline Non-mycorrhizal infection (\%) & $3.5^{\mathrm{a}}(1.4)$ & $3.8^{\mathrm{a}}(2.1)$ & $2.6^{\mathrm{a}}(1.7)$ & $3.4^{\mathrm{a}}(1.4)$ \\
\hline \multicolumn{5}{|l|}{ Sterile + pathogens/parasites } \\
\hline Mycorrhizal colonization (\%) & $0^{\mathrm{a}}(0)$ & $0^{\mathrm{a}}(0)$ & $0^{\mathrm{a}}(0)$ & $0^{\mathrm{a}}(0)$ \\
\hline Non-mycorrhizal infection (\%) & $33.3^{\mathrm{a}}(4.6)$ & $21.7^{b}(3.5)$ & $18.0^{\mathrm{b}}(3.0)$ & $15.4^{\mathrm{b}}(3.2)$ \\
\hline \multicolumn{5}{|l|}{ Field soil } \\
\hline Mycorrhizal colonization (\%) & $22.2^{\mathrm{a}}(3.0)$ & $28.7^{\mathrm{a}}(3.5)$ & $25.3^{\mathrm{a}}(4.2)$ & $21.0^{\mathrm{a}}(4.1)$ \\
\hline Non-mycorrhizal infection (\%) & $38.6^{\mathrm{a}}(5.3)$ & $19.6^{\mathrm{b}}(3.1)$ & $16.2^{\mathrm{b}}(2.8)$ & $16.4^{\mathrm{b}}(3.4)$ \\
\hline
\end{tabular}

Notes: Values represent the mean (with SE in parentheses). Different lowercase letters represent significant differences among the plant species richness treatments following ANOVA and Tukey post hoc tests $(P<0.05)$. 
diverse communities was $35 \%$ greater than per capita productivity of plants grown in soil from the monocultures $\left(F_{2,140}=5.70, P=0.004\right.$; Fig. 3F $)$. Plant productivity was significantly lower in monoculture plots than in 4-species ( $t$ value $=2.76, P=0.0066$ ) and 16 -species plots $(t$ value $=3.78, P=0.0002)$, with productivity in the latter two diversity levels not differing significantly $(t$ value $=1.18, P=0.238$ ). The incidence of disease differed across diversity treatments $\left(F_{2,140}=3.89, P=0.023\right.$; Fig. $\left.3 \mathrm{E}\right)$, and was $20 \%$ greater in plants grown in soils obtained from monoculture plots than the 16-species plots. Disease severity showed a similar trend, with a $19 \%$ higher disease severity in the monocultures than in the high-diversity plots (Fig. 3D), but with higher variances these differences were not significant. There were no significant species $\times$ treatment interactions, suggesting that species did not differ in their response to the experimental treatment and that no single species was responsible for the observed patterns. Variation in $\mathrm{N}$ across diversity treatments did not explain our findings: net soil $\mathrm{N}$ mineralization and soil solution $\mathrm{N}$ concentration did not vary significantly with diversity during the study period in the sampled plots $\left(F_{2,63}=0.41, P=0.66\right.$ and $F_{2,63}=1.13, P=0.33$ respectively; Reich et al. 2001).

\section{Discussion}

Our findings demonstrate that while both niche complementarity and density-dependent effects can theoretically produce a saturating diversity-productivity curve, soil-borne microbes were the major determinant of the diversity-productivity relationship in our study systems. In both grasslands, soil pathogens/parasites reduced productivity at low diversity (Figs. 2, 3F). Thus, less diverse communities are less productive, in large part, because plants suffer far more from host-specific soil microbes than in more diverse communities (Klironomos 2002, Fox 2003). When diversity increases, however, the probability of an individual plant growing near a conspecific decreases, resulting in a lower probability of infection (Mitchell et al. 2002, 2003). Reduced host-specific disease with increasing diversity in experiment 2 (Figs. 3D, E), and the significantly higher non-mycorrhizal fungal infection in the low diversity communities of experiment 1 (Table 1), both support this assertion. In the first experiment, the plateau in productivity and convergence of all treatments at high diversity (Fig. 2), where detrimental soil microbes were sparse, suggests that ecosystem productivity becomes resource limited when diversity is high enough to reduce the detrimental effects of soil biota.

The presence of AMF increased plant productivity, possibly by increasing resource availability to host plants, as well as protecting host plants from soil pathogens. When resource competition is intense, AMF may increase productivity by enhancing plant resource uptake, especially phosphorus (Koide 1991). In diverse plant communities, where AMF are also diverse, AMF networks
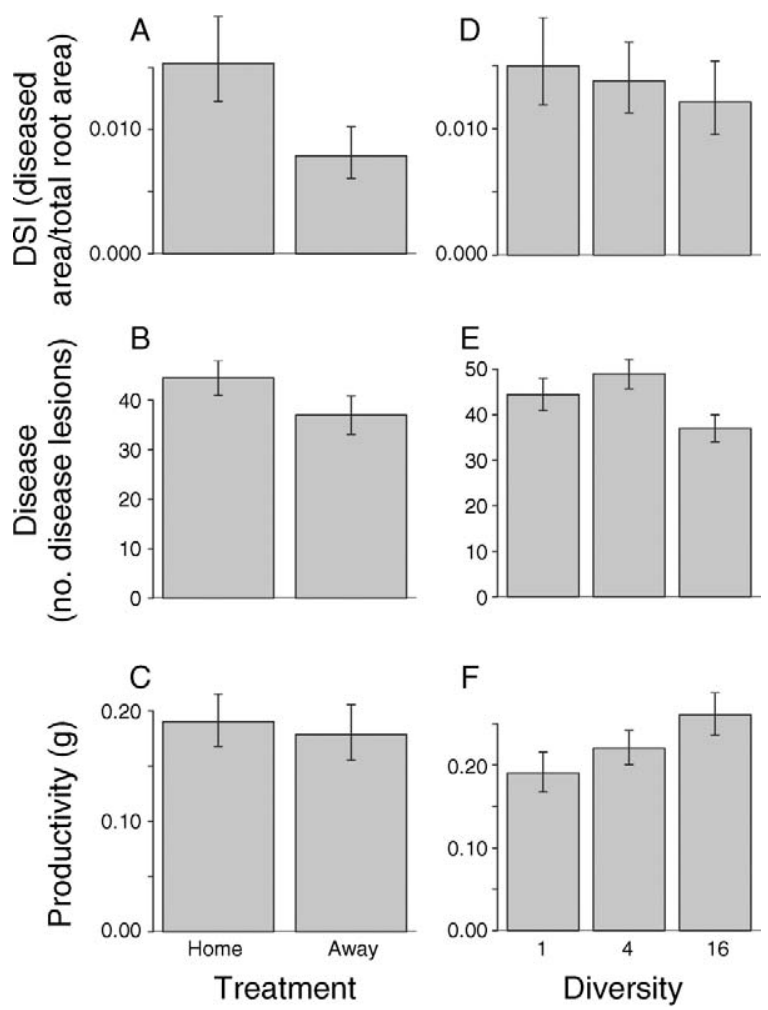

FIG. 3. Disease severity (DSI; proportion of root length with disease lesions), the incidence of disease (number of root disease lesions), and productivity (biomass) of grassland seedlings from five-year-old experimental plant communities. Panels $\mathrm{A}, \mathrm{B}$, and $\mathrm{C}$ represent seedlings grown in soils taken from plant monoculture plots in which conspecifics were grown (Home) and in which another species was grown (Away). We used 1-3 replicates per treatment, depending on seedling germination (97 individuals total). Panels D, E, and F are for seedlings grown in soil from plots of 1,4 , and 16 species $(n=48$, 55 , and 45 , respectively). Analyses included both main effects and interaction terms; interaction terms were not significant and thus were removed from the model. Error bars represent $\pm \mathrm{SE}$ (back-transformed to a nonlogarithmic scale when appropriate). Note the different $y$-axes scale numbers.

may increase community productivity through resource sharing (Simard and Durall 2004). In addition, AMF may confer protection from soil pathogens to their plant hosts (e.g., Sikes et al. 2009). Thus, both increased nutrient uptake and protection from pathogens could explain higher productivity when AMF are present.

By ignoring soil biota, and particularly the role of pathogens, previous studies may have overestimated the role of resource utilization (niche complementarity or sampling effects) as the main driver of the asymptotic diversity-productivity relationship. The modest linear increase in productivity from low to high diversity in sterilized soils lacking microbes (Fig. 2) is consistent with the occurrence of differential resource utilization among species (Tilman et al. 1997, 2001, Fargione et al. 2007). However, this increase was 10 -fold lower than when non-mycorrhizal soil biota were present, suggest-

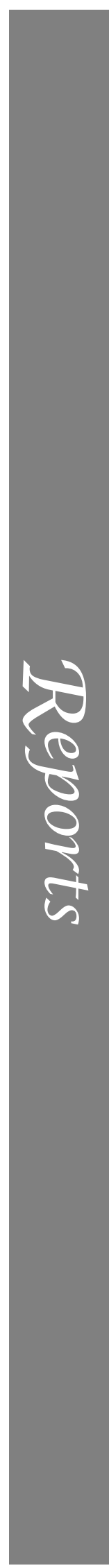


ing that resource utilization played a subordinate role to the effects of soil biota. In addition, the curve shape and amplitude in untreated field soils, which contained a complex community of soil biota, were nearly identical to the pathogen/parasite soils (Fig. 2), suggesting that pathogens and parasites, rather than AMF, soil fauna, or niche complementarity, were largely responsible for the strong asymptotic diversity-productivity relationship found in the untreated soil.

The significantly higher amount of non-mycorrhizal infection of plants in low-diversity plots in experiment 1 (Table 1) and the 20-54\% higher level of disease in plants grown in "home" soil than in "away" soil found in experiment 2 (Fig. 3A) suggest that higher disease at low diversity was caused by a higher density or effect of host-specific soil microbes. Consistent with our findings, disease caused by host-specific soil microbes have been shown previously to lead to negative plant-soil feedbacks, and these feedbacks are believed to maintain species diversity and influence productivity in many ecosystems (e.g., Bever et al. 1997, Knops et al. 1999, Klironomos 2002, van der Heijden et al. 2008, Mangan et al. 2010). Our findings are also consistent with studies that found an increase in host-specific foliar pathogens with decreasing diversity in grasslands (e.g., Mitchell et al. 2002, 2003), as well as with higher disease in agricultural monocultures compared to natural ecosystems (reviewed by Finckh and Wolfe 2006). Thus, as diversity decreases, the relative abundance of the remaining species increases, thus increasing rates of host-specific disease transmission.

The maintenance of plant species diversity and ecosystem productivity in natural ecosystems may both be linked via a common mechanism: negative densitydependent responses of plants to natural enemies. The presence of host-specific enemies, such as soil pathogens and parasites, may play an important role in explaining the stable maintenance of species diversity in many ecosystems (e.g., Klironomos 2002, Mangan et al. 2010). Higher disease levels at low diversity resulting from negative density-dependent interactions with soil enemies suggest that host-specific microbes can regulate species diversity (in concert with other drivers), which in turn may reduce ecosystem productivity. This phenomenon is also found in agricultural systems, where increasing crop diversity via species and genotype interspersing significantly reduces disease and increases productivity (Zhu et al. 2000). Historically, the maintenance of diversity via density-dependent mortality from host-specific enemies (e.g., reviewed by Carson et al. 2008) and the diversity-productivity relationship (e.g., Naeem et al. 1994, Tilman et al. 1997, 2001), two major themes of community and ecosystem ecology, have been treated separately (Worm and Duffy 2003); however, our data suggest that they are interrelated processes that should be examined together. Moreover, decreasing species diversity remains a serious threat to ecosystem functioning because the negative effects of host-specific enemies increase in lower-diversity ecosystems, which substantially suppress productivity.

\section{ACKNOWLEDGMENTS}

We thank L. Poorter and two anonymous reviewers for helpful comments on the manuscript. This work was supported by the DOE Program for Ecological Research DE-FG0296ER62291, NSF LTER DEB-0080382, NSF DEB-0614406, NSF Microbial Observatories Grant 9977907, a Discovery Grant from the Natural Sciences and Engineering Research Council of Canada, and the University of Wisconsin-Milwaukee Research Growth Initiative program.

\section{Literature Cited}

Bever, J. D., K. Westover, and J. Antonovics. 1997. Incorporating the soil community into plant population dynamics: the utility of the feedback approach. Journal of Ecology 85:561-573.

Bradford, M. A., et al. 2002. Impacts of soil faunal community composition on model grassland ecosystems. Science 298:615-618.

Brundrett, M. C., Y. Piché, and R. L. Peterson. 1984. A new method for observing the morphology of vesicular-arbuscular mycorrhizae. Canadian Journal of Botany 62:2128-2134.

Carson, W. P., J. Anderson, E. G. Leigh, and S. A. Schnitzer. 2008. Challenges associated with testing and falsifying the Janzen-Connell hypothesis: a review and critique. Pages 210 241 in W. P. Carson and S. A. Schnitzer, editors. Tropical forest community ecology. Wiley-Blackwell Publishing, Oxford, UK.

Fargione, J., D. Tilman, R. Dybzinski, J. HilleRisLambers, C. Clark, W. S. Harpole, J. M. H. Knops, P. B. Reich, and M. Loreau. 2007. From selection to complementarity: shifts in the causes of biodiversity-productivity relationships in a long-term biodiversity experiment. Proceedings of the Royal Society B 274:871-876.

Finckh, M. R., and M. S. Wolfe. 2006. Diversification strategies. Pages 269-307 in B. M. Cooke, D. G. Jones, and B. Kay, editors. The epidemiology of plant diseases. Springer, Dordrecht, The Netherlands.

Fox, J. W. 2003. The long-term relationship between plant diversity and total plant biomass depends on the mechanism maintaining diversity. Oikos 102:630-640.

HilleRisLambers, J., W. S. Harpole, D. Tilman, J. M. H. Knops, and P. B. Reich. 2004. Mechanisms responsible for the positive diversity-productivity relationship in Minnesota grasslands. Ecology Letters 7:661-668.

Hooper, D. U., et al. 2005. Effects of biodiversity on ecosystem functioning: a consensus of current knowledge. Ecological Monographs 75:3-35.

Hooper, D. U., and J. S. Dukes. 2004. Overyielding among plant functional groups in a long-term experiment. Ecology Letters 7:95-105.

Huston, M. A. 1997. Hidden treatments in ecological experiments: re-evaluating the ecosystem function of biodiversity. Oecologia 108:449-460.

Klironomos, J. N. 2002. Feedback with soil biota contributes to plant rarity and invasiveness in communities. Nature 417:6770 .

Klironomos, J. N., J. McCune, M. Hart, and J. Neville. 2000. The influence of arbuscular mycorrhizae on the relationship between plant diversity and productivity. Ecology Letters $3: 137-141$.

Knops, J. M. H., D. Tilman, N. M. Haddad, S. Naeem, C. E. Mitchell, J. Haarstad, M. E. Ritchie, K. M. Howe, P. B. Reich, E. Siemann, and J. V. Groth. 1999. Effects of plant species richness on invasion dynamics, disease outbreaks, insect abundances and diversity. Ecology Letters 2:286-293.

Koide, R. T. 1991. Nutrient supply, nutrient demand and plant response to mycorrhizal infection. New Phytologist 117:365386. 
Kulmatiski, A., K. H. Beard, J. Stevens, and S. M. Cobbold. 2008. Plant-soil feedbacks: a meta-analytical review. Ecology Letters 11:980-992.

Mangan, S. A., S. A. Schnitzer, E. A. Herre, K. Mack, M. Valencia, E. Sanchez, and J. D. Bever. 2010. Negative plantsoil feedback predicts tree-species relative species abundance in a tropical forest. Nature 466:752-755.

Maron, J. L., M. Marler, J. Klironomos, and C. Cleveland. In press. Soil fungal pathogens and the relationship between plant diversity and productivity. Ecology Letters.

McGonigle, T. P., M. H. Miller, D. G. Evans, G. L. Fairchild, and J. A. Swan. 1990. A new method which gives an objective measure of colonization of roots by vesicular-arbuscular mycorrhizal fungi. New Phytologist 115:495-501.

Mills, K. E., and J. D. Bever. 1998. Maintenance of diversity within plant communities: soil pathogens as agents of negative feedback. Ecology 79:1595-1601.

Mitchell, C. E. 2003. Trophic control of grassland production and biomass by pathogens. Ecology Letters 6:147-155.

Mitchell, C. E., P. B. Reich, D. Tilman, and J. V. Groth. 2003. Effects of elevated $\mathrm{CO}_{2}$, nitrogen deposition, and decreased species diversity on foliar fungal plant disease. Global Change Biology 9:438-451.

Mitchell, C. E., D. Tilman, and J. V. Groth. 2002. Effects of grassland plant species diversity, abundance, and composition on foliar fungal disease. Ecology 83:1713-1726.

Motulsky, H., and A. Christopoulos. 2004. Fitting models to biological data using linear and nonlinear regression: a practical guide to curve fitting. Oxford University Press, Oxford, UK.
Naeem, S., L. J. Thompson, S. P. Lawler, J. H. Lawton, and R. M. Woodfin. 1994. Declining biodiversity can alter the performance of ecosystems. Nature 368:734-737.

Reich, P. B., et al. 2001. Plant diversity enhances ecosystem responses to elevated $\mathrm{CO}_{2}$ and nitrogen deposition. Nature 410:809-812.

Sikes, B. A., K. Cottenie, and J. N. Klironomos. 2009. Plant and fungal identity determines pathogen protection of plant roots by arbuscular mycorrhizas. Journal of Ecology 97:1274-1280.

Simard, S. W., and D. M. Durall. 2004. Mycorrhizal networks: a review of their extent, function, and importance. Canadian Journal of Botany 82:1140-1165.

Tilman, D., S. Naeem, J. M. H. Knops, P. B. Reich, E. Siemann, D. Wedin, M. Ritchie, and J. H. Lawton. 1997. Biodiversity and ecosystem properties. Science 278:18661867.

Tilman, D., P. B. Reich, J. M. H. Knops, D. Wedin, T. Mielke, and C. Lehman. 2001. Diversity and productivity in a longterm grassland experiment. Science 294:843-845.

van der Heijden, M. G. A., R. D. Bardgett, and N. M. van Straalen. 2008. The unseen majority: soil microbes as drivers of plant diversity and productivity in terrestrial ecosystems. Ecology Letters 11:296-301.

Wardle, D. A. 2002. Communities and ecosystems: linking the aboveground and belowground components. Princeton University Press, Princeton, New Jersey, USA.

Worm, B., and J. E. Duffy. 2003. Biodiversity, productivity and stability in real food webs. Trends in Ecology and Evolution 18:628-632.

Zhu, Y., et al. 2000. Genetic diversity and disease control in rice. Nature 406:718-722.

\section{APPENDIX A}

Additional details describing the non-neutral theoretical model (Ecological Archives E092-026-A1).

\section{APPENDIX B}

Additional methodological details for experiments 1 and 2 (Ecological Archives E092-026-A2).

\section{APPENDIX C}

Additional discussion on soil sterilization (Ecological Archives E092-026-A3).

\section{APPENDIX D}

A table showing the performance of each plant species in each of the species richness treatments (Ecological Archives E092-026A4). 